\title{
Atypical Presentation of Bilateral Retinoblastoma with Floaters and Sub-Internal Limiting Membrane Seeds in an 11-Year-Old Asian Indian Male
}

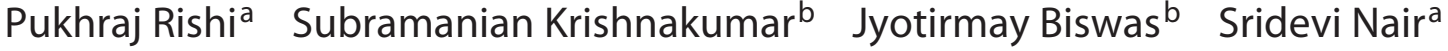 \\ a Shree Bhagwan Mahavir Vitreoretinal Services, Sankara Nethralaya, Chennai, India; b Larson and Toubro Department of \\ Ocular Pathology, Vision Research Foundation, Sankara Nethralaya, Chennai, India
}

\section{Established Facts}

- It is known that the mean age of presentation for bilateral retinoblastoma is 12 months.

- Retinoblastoma most often occurs as an intraocular tumor.

\section{Novel Insights}

- Older children can present with bilateral retinoblastoma.

- Retinoblastoma can present with floaters and sub-internal limiting membrane seeds.

\section{Keywords}

Atypical manifestation of retinoblastoma $\cdot$ Retinoblastoma

\begin{abstract}
Purpose: To report bilateral retinoblastoma in an 11-yearold child presenting with floaters and sub-internal limiting membrane (sub-ILM) seeds. Method: An 11-year-old child presented with floaters of 4 months' duration. Examination revealed circumscribed, whitish, subhyaloid, floccular nodules in the juxtapapillary region of both eyes. No solid tumor was seen. Swept-source optical coherence tomography revealed moderately reflective echoes in the sub-ILM space. Vitreous aspiration of sub-ILM deposits and cytopathological examination revealed retinoblastoma. Intravitreal melphalan $(20 \mu \mathrm{g} / 0.02 \mathrm{~mL})$ was followed by 6 monthly cycles of high-dose systemic chemotherapy (vincristine, etoposide,
\end{abstract}

carboplatin). Metastatic workup and genetic testing for $R B 1$ mutational screening were negative. Ocular lesions resolved after 13 weeks of treatment. Brain metastases developed after 20 weeks and were treated with radiation. Bilateral vitreous seeds recurred at 44 weeks and were treated with intravitreal chemotherapy (melphalan $20 \mu \mathrm{g} / 0.02 \mathrm{~mL}$ and topotecan $20 \mu \mathrm{g} / 0.02 \mathrm{~mL}$ ). There was no extra-ocular spread from sclerotomy sites. Results: Retinoblastoma and brain metastases resolved with multimodal treatment without recurrence at 59 weeks of follow-up. Conclusion: Atypical manifestation of retinoblastoma can be seen in older children presenting with "floaters" and bilateral deposits of sub-ILM seeds, without solid tumor.

c) 2018 S. Karger AG, Basel

Meeting presentation: International Society of Ocular Oncology meeting, Sydney, March 24-28, 2017.

\section{KARGER}

(c) 2018 S. Karger AG, Basel

E-Mail karger@karger.com

www.karger.com/oop
Dr. Pukhraj Rishi, MD, FRCS

Medical Research Foundation, Sankara Nethralaya

No. 18, College Road

Nungambakkam, Chennai, Tamil Nadu 600016 (India)

E-Mail docrishi@yahoo.co.in 


\section{Introduction}

Retinoblastoma (RB) is an uncommon intraocular malignancy of early childhood that frequently presents with leukocoria, strabismus, or proptosis. Bilateral cases usually present at around 12 months, while the diagnosis of unilateral cases peaks at around 24 months. The diagnosis of RB in children more than 6 years of age is uncommon.

\section{Case Report}

An 11-year-old male child presented with floaters in both eyes of 4 months' duration and was referred with a diagnosis of sarcoidosis. Biomicroscopic examination revealed occasional vitreous cells and a circumscribed collection of whitish, fluffy nodules and fine deposits at the juxtapapillary region in both eyes (Fig. 1a, b). There was no history of previous treatment for $\mathrm{RB} /$ family history of RB. Fluorescein angiography revealed blocked fluorescence corresponding to the aggregated seeds (Fig. 1c, d). Swept-source optical coherence tomography revealed moderately reflective dot-like echoes in the sub-internal limiting membrane (sub-ILM) space
(Fig. 1e, f). No solid tumor was seen in either eye; ultrasound scan was normal in both eyes (Fig. 1g, h). Visual acuity was 20/20, bilaterally. Written informed consent was obtained. Diagnostic vitrectomy of the right eye with aspiration of sub-ILM deposits and cytopathological examination revealed cohesive malignant round cells with a high nucleo-cytoplasmic ratio suggestive of RB (Fig. 1ik). Magnetic resonance imaging (MRI) of the brain and orbits ruled out any extraocular or central nervous system involvement. Treatment was started on the same day with intravitreal melphalan $(20 \mu \mathrm{g} / 0.02 \mathrm{~mL})$ in the right eye. Triple freeze-thaw cryotherapy was done to the injection site. High-dose systemic chemotherapy for 6 monthly cycles (vincristine $0.05 \mathrm{mg} / \mathrm{kg}$, carboplatin $28 \mathrm{mg} /$ $\mathrm{kg}$, etoposide $12 \mathrm{mg} / \mathrm{kg}$ on day 1 , and $12 \mathrm{mg} / \mathrm{kg}$ on day 2) was initiated. Two days later, intravitreal melphalan $(20 \mu \mathrm{g} / 0.02 \mathrm{~mL})$ was injected in the left eye. Triple freeze-thaw cryotherapy was done to the injection site. Metastatic workup was negative for malignant cells in bone marrow aspirate and cerebrospinal fluid (CSF). Genetic testing was negative for any pathogenic/likely pathogenic $R B 1$ gene mutation. Intravitreal melphalan $(20 \mu \mathrm{g} / 0.02 \mathrm{~mL})$ was repeated after 4 weeks in both eyes, with a gap of 2 days. Triple freeze-thaw cryotherapy was done to the injection site. The ocular lesions were completely resolved at 13 weeks of treatment (Fig. 2a, b). At 20 weeks from presentation, MRI and positron emission tomography-computed tomography (PET-CT) (brain and orbits)
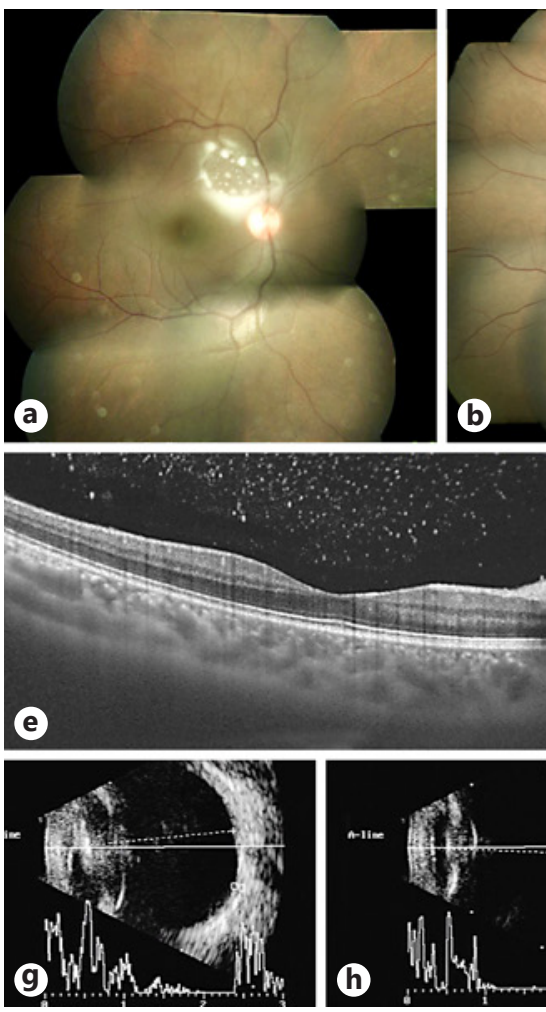

(b)
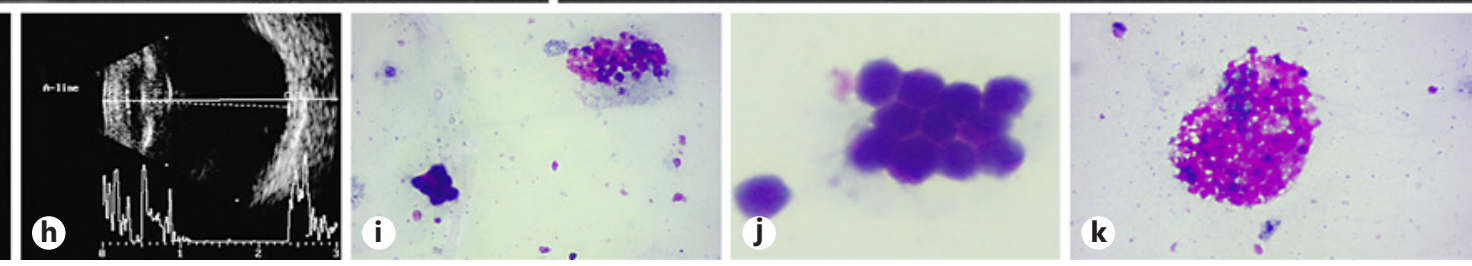

Fig. 1. At presentation: fundus montage showing sub-ILM refractile whitish deposits around the arcades in OD (a) and OS (b). Arteriovenous phase of fluorescein angiogram OD (c) and OS (d) reveals blocked fluorescence corresponding to the preretinal deposits. There is no evidence of vascular leakage/staining ruling out inflammation or neovascularization. swept-source optical coher- ence tomography OD (e) and OS (f) showing incomplete PVD with sub-ILM moderately reflective echoes causing shadowing superonasal to the fovea and superior to disc. B-scan ultrasonography OD (g) and OS (h) showing normal choroidal thickness. Cytopathological evaluation reveals clump of round to oval tumor cells with necrotic retinoblastoma cells (i-k). 
revealed an enhancing mass lesion in the basal ganglia, suggestive of metastasis (Fig. 2c). The patient was treated with palliative whole-brain external beam radiation therapy. MRI 16 weeks after starting radiation therapy showed near-complete regression of brain metastasis (Fig. 2d).

Forty-four weeks from the time of presentation, the patient developed recurrent vitreous seeds in both eyes and he received intravitreal chemotherapy (intravitreal melphalan $20 \mu \mathrm{g} / 0.01 \mathrm{~mL}$ and topotecan $20 \mu \mathrm{g} / 0.01 \mathrm{~mL}$ following which the eye lesions resolved completely (Fig. 2a, b). PET-CT done at 57 weeks from the time of presentation showed complete resolution of brain lesions. As per institutional policy, IRB approval is not required for publication of case reports.

\section{Discussion}

RB presents in 4 different growth patterns: endophytic growth pattern (towards vitreous), exophytic growth pattern (towards choroid), mixed exophytic and endophytic growth pattern, and diffuse infiltrating growth pattern. Diffuse infiltrating RB is rare and is characterized by plaque-like thickening of the retina without a discrete mass lesion. However, there is often an accompanying retinal detachment with diffusely thickened retina. Other possible clinical situations where RB could present without a discrete mass lesion are in cases of diffuse anterior $\mathrm{RB}$, or spontaneously regressed/necrotic $\mathrm{RB}$. The possibility of a bilateral RB spontaneously regressing in both eyes together is unusual but not impossible.
Our patient's presentation was unusual in a number of aspects such as the age of presentation, presenting symptoms of floaters, symmetrical nature and site of lesions, and the indolent nature of the disease. Our patient, de-
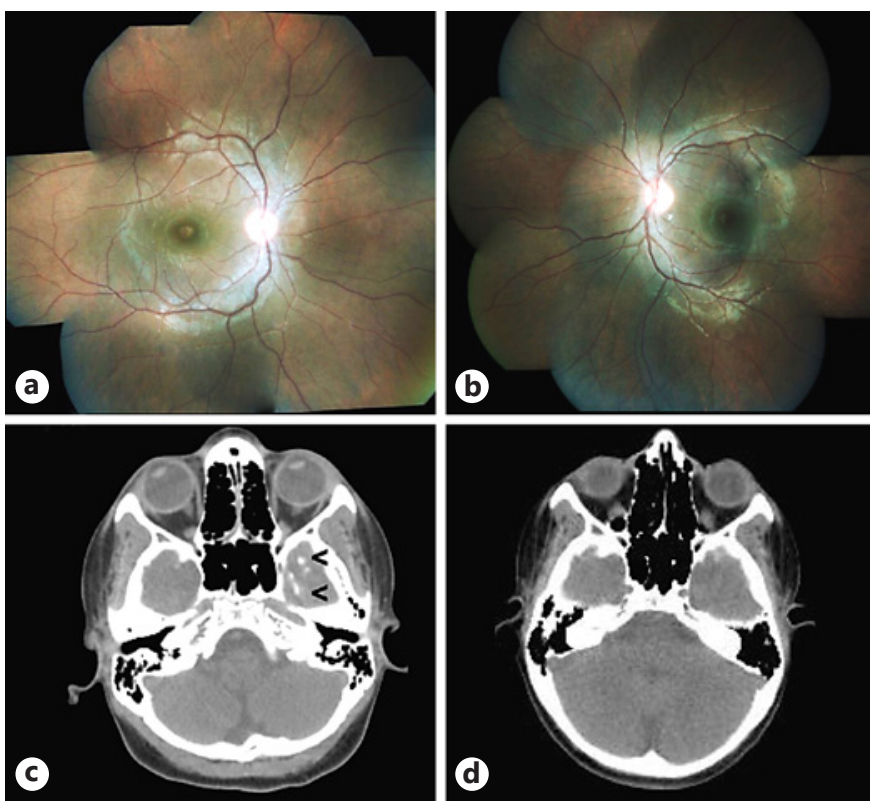

Fig. 2. Complete resolution of tumor deposits after treatment, maintained till 1 year from last intervention OD (a) and OS (b). CT brain image showing the metastatic lesions in basal ganglia at 20 weeks from presentation (c, arrowheads). CT brain image showing resolution of the lesions after radiation therapy $(\mathbf{d})$.

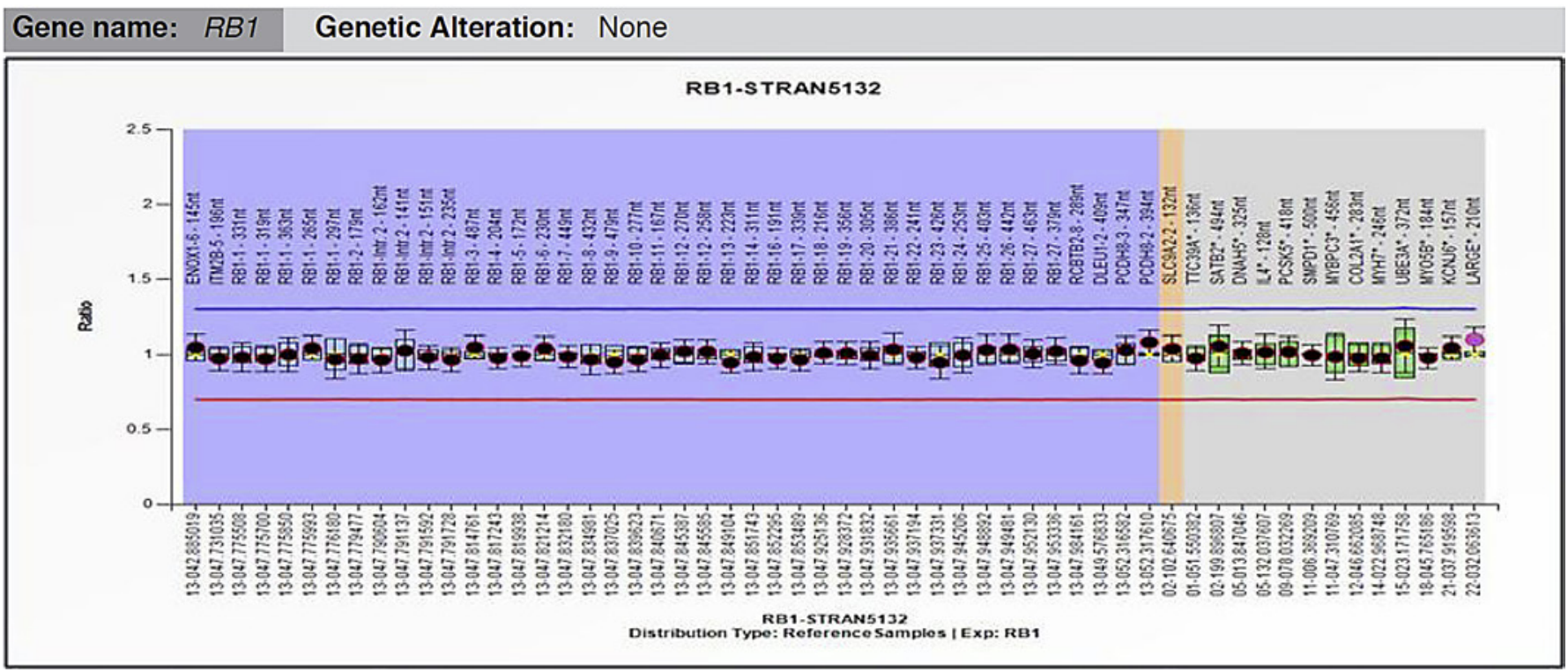

Fig. 3. Multiplex ligation-dependent probe amplification data from the patient showing normal copy of all exons of the $R B 1$ gene.

Atypical RB with Bilateral sub-ILM Seeds in an 11-Year-Old Male
Ocul Oncol Pathol 2018;4:309-312

DOI: $10.1159 / 000486341$ 
spite having a bilateral symmetrical disease, tested negative for the germline disease causing RB1 mutation (nongermline $R B 1$ mutation could not be ruled out) and thus had bilateral nonheritable RB [1]. This is not explained sufficiently by the Knudson 2-hit hypothesis. The majority (95\%) of the bilateral RB patients have germline $R B 1$ mutations, while in the remaining $5 \%$ of patients, it could be attributed to low-level mosaicism. This could offer an explanation for the possibility in our patient. Farkas and Mausolf [2] described a patient with isolated foci of subretinal RB seeds without an associated retinal detachment or the disruption of the external limiting membrane. In our patient, the deposits were primarily limited to the sub-ILM space. Even though no pathogenic/likely pathogenic $R B 1$ gene variant was observed in our patient, and the $R B 1$ gene is $100 \%$ covered with next-generation sequencing, there are some limitations in the technology as large insertions, deletions, duplications, inversions and complex rearrangements cannot be characterized accurately, since it uses short-read sequencing data [3]. Multiplex ligation-dependent probe amplification (SALSA MLPA P047-RB1-D1-0214 [D1] kit for the RB1 gene; MRC-Holland, the Netherlands) was done, and was negative for $R B 1$ mutation (Fig. 3) [4]. Apart from RB1, somatic amplification of the MYCN oncogene has been found to be responsible for some cases of nonhereditary, early-onset, aggressive, unilateral RB. It accounted for only $1.4 \%$ of RB cases and had a lower median age (4.5 vs. 24 months) at diagnosis compared to those with unilateral disease and $R B 1$ gene mutations [1].

Metastasis to the brain can occur via the optic nerve, hematogenously or via the CSF. In our patient, even though optic nerve involvement was not seen by imaging, the possibility of a spread via CSF, bloodstream or the optic nerve cannot be excluded [5]. Though metastatic RB has been associated with poor prognosis, multimodal treatment with intravitreal chemotherapy, high-dose systemic chemotherapy, and external beam radiation therapy, can help in increasing the disease-free survival [6]. The presence of tumor deposits in the vitreous and subretinal space has been associated with a higher rate of recurrence, possibly due to the dis-cohesive nature of the tumor cells [7]. Our patient has a follow-up for about a year and is under continued periodic evaluation for ocular and systemic monitoring, given the high risk for recurrence/spread.

In conclusion, treating ophthalmologists must be aware of atypical manifestation of RB in older children presenting with "floaters" and bilateral deposits of subILM floccular aggregations without a solid tumor and the ophthalmic pathologist must be well aware of the morphology of RB tumor cells seen in vitreous aspirate and if adequate cells are there plan for both immunocytochemistry study using markers such as synaptophysin as well as molecular studies.

\section{Statement of Ethics}

As per institutional policy, ethics approval is not required for the publication of case reports.

\section{Disclosure Statement}

No conflicting relationship exists for any author.

\section{References}

1 Rushlow DE, Mol BM, Kennett JY, Yee S, Pajovic S, Thériault BL, Prigoda-Lee NL, Spencer C, Dimaras H, Corson TW, Pang R, Massey C, Godbout R, Jiang Z, Zacksenhaus E, Paton K, Moll AC, Houdayer C, Raizis A, Halliday W, Lam WL, Boutros PC, Lohmann D, Dorsman JC, Gallie BL: Characterisation of retinoblastomas without RB1 mutations: genomic, gene expression, and clinical studies. Lancet Oncol 2013;14:327-334.

2 Farkas TG, Mausolf FA: Unusual subretinal seeding of retinoblastoma. Am J Ophthalmol 1968;65:545-548.
3 Abel HJ, Duncavage E: Detection of structural DNA variation from next generation sequencing data: a review of informatic approaches. Cancer Genet 2013;206:432-440.

4 Ahani A, Akbari MT, Saliminejad K, Behnam B, Akhondi MM, Vosoogh P, Ghassemi F, Naseripour M, Bahoush G, Khorshid HR: Screening for large rearrangements of the RB1 gene in Iranian patients with retinoblastoma using multiplex ligation-dependent probe amplification. Mol Vis 2013;19:454462.
5 Gündüz K, Müftüoglu O, Günalp I, Unal E, Taçyildiz N: Metastatic retinoblastoma clinical features, treatment, and prognosis. Ophthalmology 2006;113:1558-1566.

6 Rodriguez-Galindo C, Wilson MW, Haik BG, Lipson MJ, Cain A, Merchant TE, Kaste S, Pratt CB: Treatment of metastatic retinoblastoma. Ophthalmology 2003;110:1237-1240.

7 Shields CL, Honavar SG, Shields JA, Demirci $\mathrm{H}$, Meadows AT, Naduvilath TJ: Factors predictive of recurrence of retinal tumors, vitreous seeds, and subretinal seeds following chemoreduction for retinoblastoma. Arch Ophthalmol 2002;120:460-464. 